\section{"Don't burn your (respiratory) bridges": comments on recognition and management of the difficult airway}

\section{Dear Editor:}

Many pediatric emergencies are characterized by a compromised airway (e.g. epiglottitis, croup, foreign body aspiration, and pediatric head and/or neck trauma). ${ }^{1}$ In these extreme situations, the urgent need to secure the airway, should not, however, preclude the proper (although at times expeditious) airway evaluation. The pre-intubation airway evaluation is noninvasive, requires no equipment, and should not take more than a minute to perform. ${ }^{2,3}$ Such examination should sequentially focus on the following:

First, the teeth [(1-4): 1. length of upper incisors, 2. overriding of maxillary teeth anterior to the mandibular teeth, 3. anterior protrusion of mandibular teeth relative to maxillary teeth, 4. inter-incisor distance].

Second, the mouth [(5-6): 5. oropharyngeal Mallampatti class, 6. narrowness of palate].

Third, the mandibular space [(7-8): 7. thyromental distance, 8. mandibular space compliance].

Fourth, the neck [(9-11): 9. length of neck, 10. thickness of neck, 11. range of motion of head and neck].

It is important to remember that none of the 11 examinations should be considered a fail-safe predictor of intubation difficulty. The more predictors used, the better the prediction accuracy. ${ }^{2}$ In pediatrics due to the special features of pediatric anatomy and physiology, the expected or unexpected difficult airway may become a challenge to pediatricians, emergency physicians and pediatric anesthesiologists. ${ }^{4}$ Therefore, in the opinion of many experts the single most important maneuver following endotracheal intubation (particularly outside of the operating room) is to confirm proper tracheal tube positioning by using non-physical (more reliable) examination techniques. ${ }^{5}$ These include the following: 2,5

First, end-tidal $\mathrm{CO}_{2}\left(\mathrm{P}_{\mathrm{ET}} \mathrm{CO}_{2}\right)$ (EasyCap) detector: cardiac output must be present to show tracheal placement of the endotracheal tube.

Second, esophageal detector device (EDD): cardiac output does not need to be present to show tracheal placement of the tracheal tube.

Third, algorithm for using the $\mathrm{CO}_{2}$ detector and EDD together.

The EasyCap and EDD are simple and easy, reliable, quick and almost fail-safe methods of confirmation of endotracheal intubation, and were included in the International Guidelines 2000 for cardiopulmonary resuscitation. ${ }^{5}$
If the patient cannot be initially intubated, then the gas exchange is dependent on adequate mask ventilation. The first component of optimal attempt at mask ventilation should be a two-person effort followed by the use of an optimal size (large enough) oropharyngeal airway (Table 1). The necessary components of optimal/best attempt at laryngoscope intubation attempt include experience of an operator, adequate muscle relaxation, optimal patient's head position, optimal external laryngoscope pressure and adequate length/type of the laryngoscope blade (Table 1$).^{2}$

Table 1 - Definitions of optimal mask ventilation and optimal laryngoscope intubation attempt

\begin{tabular}{ll}
\hline $\begin{array}{l}\text { Definition of optimal } \\
\text { mask ventilation }\end{array}$ & $\begin{array}{l}\text { Definition of optimal } \\
\text { laryngoscope intubation attempt }\end{array}$ \\
\hline $\begin{array}{l}\text { Bilateral jaw thrust } \\
\text { and mask seal } \\
\text { (requires two rescuers) }\end{array}$ & $\begin{array}{l}\text { Reasonably experienced operator } \\
\text { Muscle relaxation } \\
\text { Optimal head position } \\
\text { Optimal external laryngeal pressure } \\
\text { Change length of blade } \times 1 \\
\text { Change type of blade } \times 1\end{array}$ \\
oropharyngeal airway 1
\end{tabular}

\section{Krzysztof M. Kuczkowski}

M.D.; Professor of Anesthesiology and Reproductive Medicine; Director of Obstetric Anesthesia, Departments of Anesthesiology and Reproductive Medicine, University of California San Diego, San Diego, California, USA.

\section{References}

1. Amantea SL, Piva JP, Zanella MI, Bruno F, Garcia PC. Rapid airway access. J Pediatr (Rio J). 2003;79 Suppl 2:S127-38.

2. Benumof JL. ASA Difficult Airway Algorithm: New Thoughts and Considerations. CSA/UCSD Annual Meeting and Anesthesiology Review Course, May 22, 2004; 135-150.

3. Kuczkowski KM, Reisner LS, Benumof JL. Airway problems and new solutions for the obstetric patient. J Clin Anesth. 2003; 15:552-63.

4. Brambrink AM, Meyer RR, Kretz FJ. Management of pediatric airway-anatomy, physiology and new developments in clinical practice. Anaesthesiol Reanim. 2003;28:144-51.

5. Guidelines 2000 for cardiopulmonary resuscitation and emergency cardiovascular care. Circulation. 2000;102 Suppl I: 380-8. 


\section{Author's reply}

Appropriate airway management is of paramount importance when treating critically ill patients. It is frequently used in several medical specialties that deal with emergency care and requires qualified professionals with experience in this type of procedure. Airway establishment and maintenance is a continuous multi-faceted process that requires ability, experience and compliance with systematic steps. In his letter to the Editor, Dr. Krzysztof M. Kuczkowski, in reference to the review article published by us, ${ }^{1}$ reinforced the importance of three steps to be followed during airway management in pediatric patients. The first step is specifically concerned with preparation for airway manipulation and includes important symptomatologic aspects that should be checked in all patients, since they can provide, in a fast and noninvasive fashion, some useful information that may contribute to the success and safety of the maneuver. After that, he highlighted the importance of checking the appropriate positioning of the endotracheal tube, using specific devices incorporated into international resuscitation protocols. ${ }^{2,3}$

Finally, Dr. Kuczkowski mentions the possibility of failure, which may be avoided by way of proper mask ventilation and optimized technical conditions during the procedure, probably resulting in a favorable clinical outcome.

Actually, the issues pointed out by Dr. Krzysztof M. Kuczkowski stress the importance of systematizing airway management procedures in the pediatric population. The principles that underlie airway management in pediatric patients are virtually the same as those established for adult patients. Except for some anatomical and physiological aspects, the main differences lie in the selection of drugs and equipment to be used, which is often determined by the former characteristics. Therefore, all the issues that have been raised should be considered for a rapid and properly performed sequence intubation. ${ }^{4}$ After the preparation phase, intubation also includes the following phases: preoxygenation, pretreatment, paralysis, protection and positioning. In fact, the procedure initiates some minutes before the preparation phase and goes on for approximately 45 seconds after paralysis. This sequence of events is performed in a successive fashion in a short period of time, and after that, we have post-intubation management. ${ }^{4}$ Here, the focus should be on the appropriate positioning of the endotracheal tube, since a deeper insertion may result in the endotracheal placement of the tube, while a poor insertion is associated with a higher risk of accidental extubation. Thus, the systematic management of all phases will determine a successful procedure. With regard to the latter phase, considering the relevant issues raised by $\mathrm{Dr}$. Kuczkowski about other phases of airway management, Dr. Sunita Goel and Suan-Ling Lim bring other issues into the discussion. ${ }^{5}$ After assessing endotracheal tubes from different manufacturers, they observed some differences regarding insertion depth markings. Their observation is clinically relevant, because many Guidelines estimate insertion depth using these standard markings. Therefore, they underscore the importance of careful clinical judgment, which seems to be beyond any recommendations, as there was a wide variation in insertion depth markings.
All of these considerations show that systematization should be a continuous process that should obligatorily include all the actions and procedures concerned with airway management.

\section{Sérgio L. Amantéa}

Associate professor, Department of Pediatrics, Fundação Faculdade Federal de Ciências Médicas de Porto Alegre (FFFCMPA). Chief of the Pediatric Emergency Service, Hospital da Criança Santo Antônio (HCSA), Complexo Hospitalar Santa Casa, Porto Alegre, RS, Brazil.

\section{References}

1. Amantéa SL, Piva JP, Zanella MI, Bruno F, Garcia PC. Acesso rápido à via aérea. J Pediatr (Rio J). 2003;79 Suppl 2:S127-38.

2. The American Heart Association in Collaboration with the International Liaison Committee on Resuscitation. Guidelines 2000 for cardiopulmonary resuscitation and emergency cardiovascular care. Part 9: pediatric basic life support. Circulation. 2000;102 Suppl I:253-90.

3. The American Heart Association in Collaboration the International Liaison Committee on Resuscitation. Guidelines 2000 for cardiopulmonary resuscitation and emergency cardiovascular care. Part 10: pediatric advanced life support. Circulation. 2000;102 Suppl I:291-342.

4. Walls RM. Rapid sequence intubation. In: Walls RM, Luten RC, Murphy MF, Schneider RE, editors. Manual of Emergency Airway Management.Philadelphia: Lippincott, Williams \& Wilkins; 2000. p. 8-15.

5. Goel S, Lim SL. The intubation depth marker: the confusion of the black line. Paediatr Anaesth. 2003;13:283-5.

\section{Low birth weight and early weaning: new risk factors for atherosclerosis}

\section{Dear Editor}

The study by Romaldini et al. ${ }^{1}$ on the risk factors for atherosclerosis in children and adolescents, regarded as the main cause of death in the world and in Brazil, was very appropriate. The authors detected one or more risk factors for atherosclerosis in $41 \%$ of 109 children and adolescents with family history of early heart disease. The higher the number of risk factors, the higher the probability of disease, since the effects are multiplied. Therefore, the recent publications of scientific evidence regarding two new risk factors for cardiovascular diseases, namely low birth weight and absence of breastfeeding, are of utmost importance, especially to those who provide child care.

Singhal et al. ${ }^{2}$ suggest that nutrition during childhood permanently affects the lipoproteic profile throughout life and that breastmilk has a protective effect on this profile. In a recent randomized clinical trial, they found a lower cholesterol concentration and a lower LDL/HDL ratio in adolescents with a preterm birth who had been breastfed. The ALSPAC (Avon Longitudinal Study of Parents and Children) also 